\title{
VASCULAR RESPONSES TO CATECHOLAMINE OF THE SINUS NODE ARTERY OF THE DOG
}

\author{
Shigetoshi Chiba AND Koroku Hashimoto \\ Department of Pharmacology, Tohoku University \\ School of Medicine, Sendai
}

\section{INTRODUCTION}

On the coronary circulation, the effect of catecholamines was disputed by many investigators, and there is general agreement that catecholamines increase the coronary blood flow. However, some researchers attributed this vasodilatation to myocardial stimulation and consequent metabolic vasodilatation rather than to direct action to the coronary arter $\mathrm{y}^{1,2,3)}$. On the other hand, ZUBERBUHLER and BOHR ${ }^{4}$ reported that epinephrine and norepinephrine caused contraction of the isolated coronary artery strips after beta-receptor blockade. Similarly DoutheIl et $a l^{5}{ }^{5}$, GAAL et $a l^{6}{ }^{6}$, and PARRATT ${ }^{7)}$ have demonstrated alpha-receptor activity after induction of beta-receptor blockade in the anesthetized dog. Recently PITT et $a l .{ }^{8)}$ who investigated the coronary flow in the unanesthetized dog using chronically implanted electromagnetic flow transducers described both alpha- and beta-receptor activities for catecholamines in coronary arteries.

In the previous papers ${ }^{9,10)}$, the present authors described the constant pressure perfusion of the sinus node artery. This artery, the outer diameter of which is from 0.5 to $1 \mathrm{~mm}$ and is a branch of the right coronary artery, runs on the surface of the right auricle to the sinus node area. The extravascular pressure exerted by myocardial contraction will be minimum among other coronary arteries because of thin atrial muscle and low atrial pressure. Furthermore occlusion of this artery induces a positive chronotropic response of the sino-atrial node due to a baroceptive response ${ }^{9)}$, but never induces degenerative tissue damage. Then this artery is not like the ordinary coronary arteries which nourish myocardium, and may be considered as a specific coronary artery. In the present study, the authors investigated whether alphaand beta-adrenergic receptor activities could be demonstrated in this artery.

Received for publication August 15, 1969

千葉茂俊, 橋本虎六 


\section{METHODS}

Fourteen mongrel dogs of both sexes, weighing 10 to $21 \mathrm{~kg}$, were used. They were anesthetized with i.v. sodium pentobarbital, $30 \mathrm{mg} / \mathrm{kg}$. A tracheal tube was inserted, and artificial respiration was performed by use of a Bird respirator (Mark 8). The chest was opened at the right 4 th intercostal space. The pericardium was cut and the pericardial cradle was prepared for keeping the heart in the proper position. The direct perfusion of the sinus node artery (JAMES and NADEAU ${ }^{11)}$ ) was modified by the authors as follows. All experiments were performed under constant perfusion pressure at 100 $\mathrm{mmHg}$ (HAshimoto et al.,9) 1967), because the sino-atrial node is responsive to pressure changes. The change in flow rate of the sinus node artery was measured by use of an electromagnetic flowmeter (Nihon Kohden MF-2), which is sensitive to a change in the blood flow of $1 \mathrm{ml} / \mathrm{min}$. The details of the preparation were described in a previous paper ${ }^{10)}$. Both vagus nerves, however, were cut in these experiments. Two electromanometers were arranged to measure perfusion pressure and systemic arterial pressure. The electrocardiogram (ECG) (lead II) was recorded by an electrocardiograph (Nihon Kohden ME-20-TR). The heart rate was continuously recorded by a cardiotachograph (Nihon Kohden RT-2), which was triggered by the $\mathrm{R}$ wave of the ECG. Sodium heparin used in these experiments was a preparation extracted from the lung and intestinal mucous membrane of whales; 500 units $/ \mathrm{kg}$ were given at the beginning of perfusion and 200 units $/ \mathrm{kg}$ were added at $1-\mathrm{hr}$ intervals. In 13 preparations, the flow rate of the sinus node artery was $2.30 \pm 0.32 \mathrm{ml} / \mathrm{min}$ (mean \pm S.E.) under constant pressure at $100 \mathrm{mmHg}$.

The drugs used in these experiments were dopamine hydrochloride (Tokyo-kasei), dl-norepinephrine hydrochloride (Sankyo), dl-epinephrine hydrochloride (Sankyo), 1-isoproterenol hydrochloride (Nitsuken), propranolol (Sumitomo Chemicals), phentolamine hydrochloride (Ciba) and phenoxybenzamine (S.K. \& F.). The rate of injection of drug solution was fixed at $0.01 \mathrm{ml} / 4$ seconds, because $0.01 \mathrm{ml}$ of the physiological saline injected in a period of 4 seconds did not induce any remarkable vascular effect.

\section{RESULTS}

1) Vascular responses of the sinus node artery to catecholamines (FIG. 1, TABLE 1)

The selective administration of catecholamines (dopamine, norepinephrine, epinephrine and isoproterenol) into the sinus node artery caused a vasodilatation in a majority of cases. Especially, isoproterenol induced a vasodilatation in every animal and in every trial. Dopamine, norepinephrine and epinephrine induced occasionally a vasoconstrictor or combined vasodilator and constrictor response. Although these naturally occurring catecholamines produced usually a positive chronotropic response, there was no relation between the chronotropic and vasomotor responses to catecholamines. FIG. 1 shows three types of vascular response to norepinephrine, A: vasodilator response following vasoconstrictor response; B : vasodilator response; and C: vasoconstrictor response. The vascular response of each amine was almost the same and the patterns of response to catecholamines at the beginning of experiments are summarized in TABLE 1. 


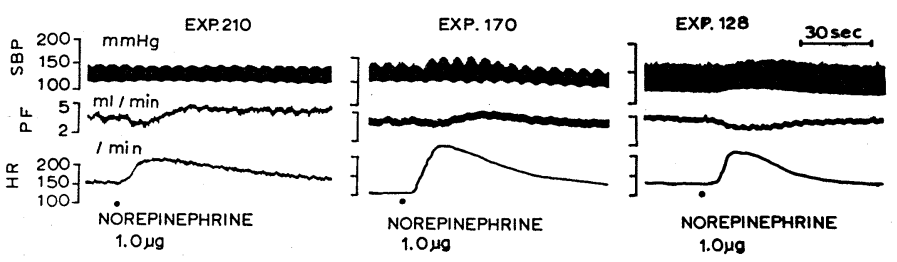

FIG. 1. Different patterns of the sinus node artery to the selective injection of norepinephrine into the sinus node artery. SBP: systemic blood pressure; PF : perfusion flow; HR: heart rate.

TABLE 1 .

Responses to catecholamines of the sinus node artery.

\begin{tabular}{|c|c|c|c|c|}
\hline \multirow{2}{*}{ Catecholamines } & \multirow{2}{*}{$\begin{array}{c}\text { Doses } \\
(\mu g)\end{array}$} & \multicolumn{3}{|c|}{ Patterns of responses } \\
\hline & & A & $\mathrm{B}$ & $\mathrm{C}$ \\
\hline Dopamine & 1.0 & $3 / 12$ & $8 / 12$ & $1 / 12$ \\
\hline Norepinephrine & 1.0 & $2 / 12$ & $9 / 12$ & $1 / 12$ \\
\hline Epinephrine & 1.0 & $2 / 11$ & $7 / 11$ & $2 / 11$ \\
\hline Isoproterenol & 0.1 & $0 / 8$ & $8 / 8$ & $0 / 8$ \\
\hline
\end{tabular}

A : combined vasoconstriction and vasodilatation,

B : vasodilatation,

C: vasoconstriction.

2) Effect of propranolol (FIG. 2)

Propranolol injected into the sinus node artery decreased the sinus rate and usually caused a decrease of the flow rate, while a larger amount of propranolol, above $10 \mu \mathrm{g}$, frequently caused an increase. A vasodilator response to catecholamines was blocked by a sufficient amount of propranolol, 1 to $10 \mu \mathrm{g}$. FIG. 2 showed that a vasodilator response caused by $1 \mu \mathrm{g}$ of each catecholamine was completely blocked by $10 \mu \mathrm{g}$ of propranolol and then a vasoconstrictor response to these catecholamines unveiled. After 30 minutes these catecholamines again caused a biphasic response as it did before propranolol treatment.

3) Effect of phentolamine and phenoxybenzamine (FIG. 3)

Phentolamine $(10 \mu \mathrm{g})$ injected into the sinus node artery caused a slight increase both in the sinus rhythm and the flow rate. This treatment prevented a vasoconstrictor response to naturally occurring catecholamine, although the acceleration of sinus rhythm was not affected. FIG. 3 showed that the vasoconstrictions induced by $1 \mu \mathrm{g}$ of norepinephrine and dopamine were prevented by selective use of $10 \mu \mathrm{g}$ of phentolamine. This effect of phentolamine disappeared $5 \mathrm{~min}$ later. The same effect was produced by $10 \mu \mathrm{g}$ of phenoxybenzamine but it lasted more than $30 \mathrm{~min}$. 


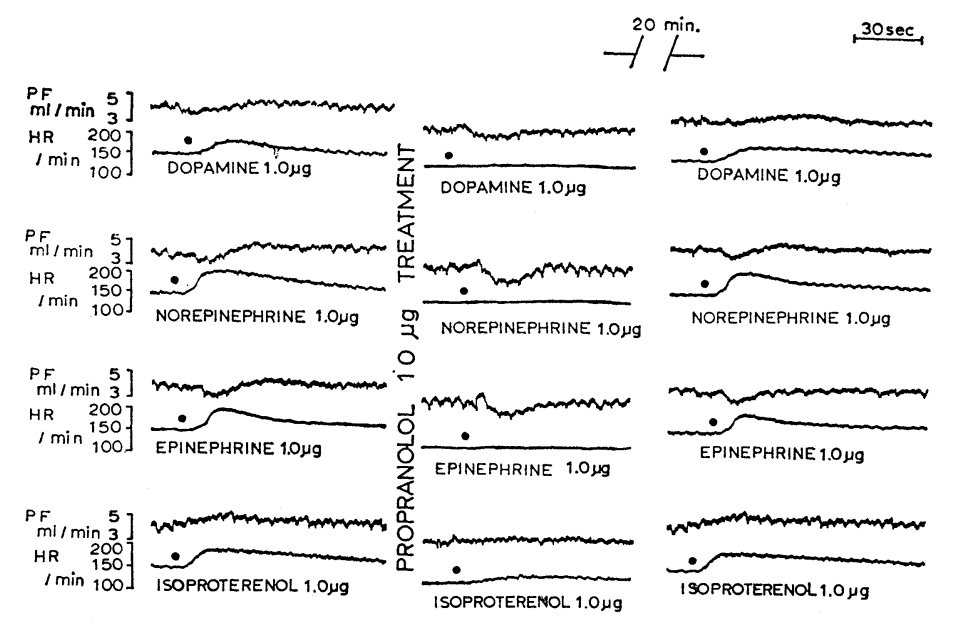

FIG. 2. Vasodilatation induced by injection of catecholamines into the sinus node artery and blocking effect of propranolol. PF : perfusion flow; HR: heart rate.

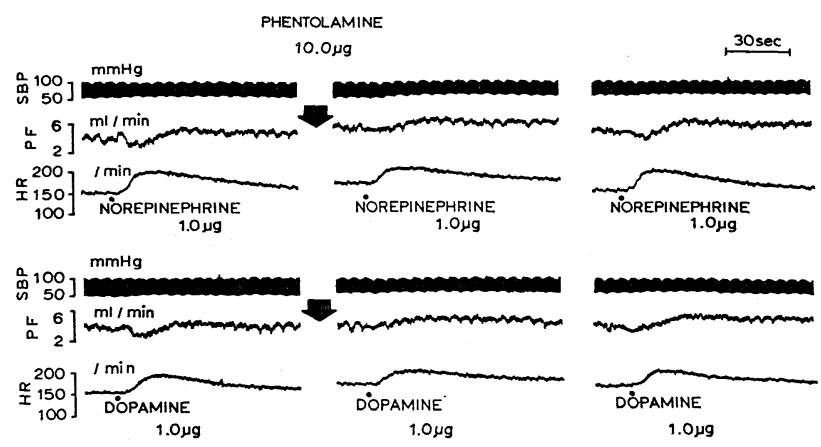

FIG. 3. Absence of vasoconstriction induced by norepinephrine and dopamine injection into the sinus node artery after phentolamine treatment. SBP : systemic blood pressure; PF : perfusion flow; HR: heart rate.

\section{DISCUSSION}

Since the first application of a beta-adrenergic blocking agent to the study on the coronary circulation was done by HASHIMото et al. ${ }^{1)}$, there have been many reports of coronary vascular responses to naturally occurring catecholamines after administration of beta-blocking agents. HASHIMOTO et al. used a bubble flow meter to measure the coronary blood flow in the Langendorff preparation perfused with the blood from a donor dog by cross circulation technique. Intra-coronary injections of epinephrine and norepinephrine produced increases in coronary flow and myocardial oxygen consumption, but after beta-adrenergic blockade by dichlorisoproterenol the same drugs reduced 
coronary flow. In the present study, the canine sinus node artery was cannulated and perfused with a constant pressure at $100 \mathrm{mmHg}$. Mean arterial inflow was measured with an electromagnetic flowmeter (Nihon Kohden MF-2). Vasodilator response was induced by catecholamines, and this was blocked by propranolol which is beta-adrenergic agent. In several dogs, a vasoconstrictor response induced by naturally occurring catecholamines (dopamine, norepinephrine and epinephrine) was completely blocked by alpha-blocking agents such as phentolamine and phenoxybenzamine.

In 1965, ZUBERBUHLER and BOHR ${ }^{4)}$, using isolated strips from small coronary arteries of dogs, demonstrated a relaxation resulting from epinephrine and norepinephrine. This relaxation was blocked by beta-adrenergic blocking agent. In contrast, strips from large coronary arteries occasionally contracted in response to catecholamines and this could be blocked by and alpha-receptor blocking agent. The sinus node artery which is small and straight runs across the surface layer of auricle to the sino-atrial node. After leaving the sino-atrial node, it branches off small arteries to the superior vena cava and the right atrial appendix. The size of this artery is intermediate between small and large coronary arteries which ZUBERBUHLER and BOHR used in their experiments. The presence of alpha- and/or beta-adrenergic receptors in the sinus node artery will probably be consistent with those results of ZUBERBUHLER and BOHR.

If the vasodilatation caused by catecholamines is ascribed to myocardial stimulation with subsequent metabolic increase, vasodilatation will last longer even after the recovery from the positive chronotropic response. The vasodilator response to catecholamines, however, disappeared keeping pace with the recovery from the positive chronotropic response. Then the increase in flow rate of the sinus node artery may probably be due to beta-adrenergic vascular relaxation. The present findings indicate the direct coronary vasodilator action of catecholamine both for ordinary myocardial arteries as well as the specific coronary artery such as the sinus node artery.

As previously reported ${ }^{9)}$, the sino-atrial node is sensitive to pressure changes in the sinus node artery, which is one of the main branches of the right coronary artery. Thus the sino-atrial node may probably respond to the change in aortic pressure. And alpha- and beta-adrenergic receptor mechanisms in this artery may be operative in the pressure dependent activity of the sino-atrial node.

\section{SUMMARY}

Constant pressure perfusion of the sinus node artery at $100 \mathrm{mmHg}$ was arranged in vagotomized dog heart in situ and adrenergic receptor mechanism of the sinus node artery was studied. Vasoconstrictor and/or dilator responses 
were obtained when naturally occurring catecholamines, i. e., dopamine, norepinephrine and epinephrine were given intra-arterially. Response to isoproterenol was exclusively vasodilatation. The vasodilator response to the catecholamines was prevented by propranolol, one of the adrenergic blocking agents, while the vasoconstrictor response was abolished by injection of alpha-adrenergic blocking agent, phentolamine or phenoxybenzamine, selectively into the sinus node artery.

It was concluded that the existence of both alpha- and beta-adrenergic receptors even in the sinus node artery which is functionally different from the ordinary myocardial arteries.

These experiments were supported partly grants of the Pharmacological Research Foundation, the Sankyo Central Laboratories and the Squibb Institute of Medical Research (U.S.A.). We are grateful to Yasuyuki SUZUKI for surgical advice in some of the experiments.

\section{REFERENCES}

1) Hashimoto, K., Shigei, T., Imai, S., Saito, Y., Yago, N., Uei, I. and Clark, R.E. Oxygen consumption and coronary vascular tone in the isolated fibrillating dog heart. Amer. J. Physiol., 198: 965-970, 1960.

2) BERne, R.M. Effect of epinephrine and norepinephrine on coronary circulation. Circulation Res., 6: 644-655, 1958.

3) Berne, R.M. Regulation of coronary blood flow. Physiol. Rev., $44: 1-29,1964$.

4) Zuberbuhler, R.C. And Bohr, D.F. Responses of coronary smooth muscle to catecholamines. Circulation Res., 16:431-440, 1965.

5) Doutheil, U., Ten Bruggencate, H.G. And Kramer, K. Coronar-vasomotorik under l-Noradrenalin und Isopropylnoradrenalin nach Blockierung der adrenergischen $\beta$-Receptoren durch Nethalide. Pfugers Arch., 281: 181-190, 1964.

6) GaAl, P.G., Kattus, A.A., Kolin, A. And Ross, G. Effects of adrenalin and noradrenalin on coronary blood flow before and after beta adrenergic blockade. Brit. J. Pharmacol., 26 : 713-722, 1966.

7) Parratt, J.R. Blockade of sympathetic beta receptors in the myocardial circulation. Brit. J. Pharmacol., 24 : 601-611, 1965.

8) Pitt, B., Elliot, E.C. And GregG, D.E. Adrenergic receptor activity in the coronary arteries of the unanesthetized dog. Circulation Res., $21: 75-84,1967$.

9) Hashimoto, K., Tanaka, S., Hirata, M. and Chiba, S. Responses in rhythmicity of the sino-atrial node to changes of pressure in the sinus node artery. Circulation Res., 21 : 297-304, 1967.

10) Hashimoto, K., Chiba, S., Tanaka, S., Hirata, M. and Suzuki, Y. Adrenergic mechanism participating in induction of atrial fibrillation by ACh. Amer. J. Physiol., 215: 1183-1191, 1968.

11) James, T.N. And Nadeau, R.A. Direct perfusion of the sinus node: An experimental model for pharmacologic and electrophysiologic studies of the heart. Henry Ford Hosp. Med. Bull., $10: 21-25,1962$. 